\title{
Cobrotoxin-containing analgesic compound to treat chronic moderate to severe cancer pain: Results from a randomized, double-blind, cross-over study and from an open-label study
}

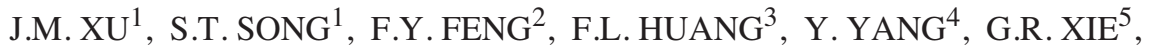

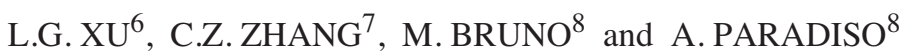 \\ ${ }^{1}$ Beijing 307 Hospital Cancer Center; ${ }^{2}$ Cancer Hospital, Chinese Academy of Medical Sciences, \\ Beijing; ${ }^{3}$ Jiangsu Province Cancer Hospital, Nanjing; ${ }^{4}$ Kunming the PLA General Hospital, Kunming; \\ ${ }^{5}$ Tianjin Cancer Hospital, Tianjin; ${ }^{6}$ Cancer Hospital, Fudan University, Shanghai; ${ }^{7}$ The Third Teaching \\ Hospital, Kunming Medical University, Kunming, P.R. China; ${ }^{8}$ National Cancer Institute, Bari, Italy
}

Received June 5, 2006; Accepted July 19, 2006

\begin{abstract}
Cobrotoxin produces intense analgesia but it has an onset of response of 1-3 h which hampers its clinical use in cancer pain. Recently, a compound analgesic formulation combining cobrotoxin, tramadol hydrochloride and ibuprofen (Compound Keluoqu, CKLQ) has become available in China. The aim of this study was to evaluate the clinical efficacy of CKLQ for moderate to severe cancer pain. A consecutive series of patients with chronic moderate to severe cancer pain was enrolled into two multicenter trials. Of the 230 eligible patients, 119 were assigned to a randomized, double-blind, cross-over study, while 111 entered an open-label study. They were all of Han-China nationality and had a mean age of 52.0 and 55.4 years and a mean body weight of 55.6 and $52.9 \mathrm{~kg}$, respectively. A total of 11 patients discontinued the study, $6(54.5 \%)$ because of insufficient pain relief and 5 due to the occurrence of adverse events. In the cross-over study, 59 patients were randomized to receive a CKLQ package with 2 CKLQ tablets (each containing $0.16 \mathrm{mg}$ cobrotoxin, $25 \mathrm{mg}$ tramadol hydrochloride and $50 \mathrm{mg}$ ibuprofen) and 2 placebo capsules, a placebo package with 2 placebo tablets and 2 placebo capsules, and an active control package with 2 tramadol hydrochloride capsules (each containing $50 \mathrm{mg}$ tramadol hydrochloride) and 2 placebo tablets ( $\operatorname{arm~A),~and~} 60$ to receive a tramadol hydrochloride package, a placebo package and a CKLQ package (arm B), sequentially and only once. Patients in the open-label study only received CKLQ and were given the option to continue for up to 7 days as long as they had
\end{abstract}

Correspondence to: Dr Angelo Paradiso, National Cancer Institute, Via Hanhemann 10, I-70126 Bari, Italy

E-mail: a.paradiso@oncologico.bari.it

Key words: cancer pain, cobrotoxin, Keluoqu, randomized clinical trial satisfactory pain relief. Pain response was classified as CR, PR and NC. CR was defined as $100 \%$ pain relief, with a pain score of 0 on a $0-10$ VAS. PR was defined as decreased to mild pain, with a pain score of no more than 4 on a 0-10 VAS. $\mathrm{NC}$ was defined as pain that either remained unchanged or that was reduced from severe to moderate at baseline, with a VAS pain score of more than 4 after treatment. One hundred and eight patients completed the cross-over study with all the three drug units. The overall rate of pain relief was 93/ $111(83.7 \%)$ for CKLQ, 75/110 (68.2\%) for tramadol hydrochloride $(\mathrm{P}=0.011)$ and $39 / 111(35.1 \%)$ for placebo $(\mathrm{P}<0.001)$. The mean duration of pain relief with CKLQ was significantly longer than that of the other two agents $(\mathrm{P}<0.001)$. Of the 35 patients who did not respond to tramadol hydrochloride, $27(77.1 \%)$ responded to CKLQ, while of the 18 who did not respond to CKLQ, 8 (55.6\%) achieved satisfactory pain control with tramadol hydrochloride. In the open-label study, the overall relief rate of a single-dose of CKLQ was 99/111 (89.2\%). A reduction in the percentage of complete relief, an increase in that of PR and a significant decrease in duration of relief were observed after continuous treatment with at least 10 doses of CKLQ. The frequency of adverse events for CKLQ was similar to that of tramadol hydrochloride. The results of the randomized, double-blind, cross-over study and the open-label study of CKLQ in cancer patients with chronic moderate to severe cancer pain suggest that the CKLQ may be valuable for the treatment of chronic moderate to severe cancer pain. However, the tolerance of CKLQ remains to be further defined.

\section{Introduction}

Opioid analgesics are generally considered to be the most effective drugs for chronic moderate to severe cancer pain and for insufficient pain relief from non-opioid analgesics $(1,2)$. However, there is a highly individual variability in response and in the incidence of adverse events (AEs) to different opioids $(3,4)$. Clinical practice guidelines for cancer pain management suggest that alternating opioids with opioids combined with other pharmacological agents (such as non- 
steroidal anti-inflammatory drugs, steroids or psychotropic drugs) to meet the individual needs of patients is an important strategy for optimizing control of cancer pain and reducing dose-limiting toxicities of opioids (5). Whether these analgesic agents in compound formulations have as effective a response and safety profile has not yet been documented.

Compound Keluoqu (CKLQ) in tablet form is a unique formulation with different analgesic mechanisms, in which cobrotoxin is combined with $1 / 2$ dose of tramadol hydrochloride $(50 \mathrm{mg})$ and $1 / 3$ dose of ibuprofen $(100 \mathrm{mg})$. Cobrotoxin is known to bind with cysteine residues of biological molecules such as nicotine acetylcholine receptor (6). The pharmacologic study of cobrotoxin, a novel analgesic toxin purified from king cobra venom, has documented its potent analgesic action involving an opioid and nitric oxide (7-9). Animal studies have shown that the response produced by cobrotoxin is long-lasting, with 6-8 $\mathrm{h}$ duration of pain relief, while its onset is slow, with maximum relief occurring between 1-3 h following administration (8). Tramadol hydrochloride, a centrally acting drug introduced in the late 1970 s, is a partial $\mu$-opioid agonist substitute which inhibits both norepinephrine (noradrenaline) and serotonin (5-hydroxytryptamine) neuronal re-uptake and facilitates their release $(10,11)$. Ibuprofen, a non-steroidal anti-inflammatory drug (NSAID), has been widely used in the treatment of rheumatic diseases and has also shown to induce a good response providing relief of mild to moderate cancer pain and of moderate to severe cancer pain when combined with opioids $(12,13)$.

Theoretically, in a complementary and/or synergistic manner, the association of cobrotoxin with tramadol and ibuprofen would decrease the amount of weak opioid (tramadol) and NSAID (ibuprofen) required, and thus decrease the incidence of weak opioid and NSAID use. Clinical studies have confirmed that CKLQ produces acceptable analgesia and response times) in the treatment of post-operative pain, with a mean duration of pain relief lasting $6.5 \mathrm{~h}$ (6). In this investigation, the aim of the cross-over study was to evaluate whether CKLQ could provide at least the same level of pain control (including analgesic intensity and duration of response) as that obtained by tramadol hydrochloride for chronic moderate to severe cancer pain, and whether it could be a realistic switching option for patients who are tolerant to tramadol hydrochloride, while that of the open-label study was to observe the toxicity and tolerance of CKLQ.

\section{Patients and methods}

Patient selection. The cross-over study and the open-label study were performed successively at 7 cancer centers. The enrollment period was from January 1999 through April 2000. Patients with chronic moderate to severe cancer pain and stable analgesic requirements $(14,15)$, aged 18 or over were considered eligible for the study. Pain intensity rated higher than 4 on a visual analogue scale (VAS) of a horizontal $10-\mathrm{cm}$ line ranging from 0 to $10(16)$, where 0 equaled no pain and 10 the worst pain imaginable.

Before enrollment, the patients' medical records were checked and the patients underwent a thorough physical examination to ensure they had no history of psychiatric disease or of drug abuse, and to check for evidence of oral, hepatic, renal or cognitive diseases that would prevent them from participating in the study. Patients discontinued any other analgesics (opioid or non-opioid) at least $8 \mathrm{~h}$ before receiving the first dose of the study medication, and controlled-release analgesics $12 \mathrm{~h}$ before. Active anticancer therapy (e.g., chemotherapy, radiotherapy, endocrine therapy) was not permitted in the three weeks before starting therapy with the study medication.

Exclusion criteria were: a history of hypersensitivity to any related drug component, functional impairment of the kidney or liver, significantly impaired ventilatory function, current use of another investigational drug, pregnancy or lactation, unwillingness or inability to cooperate or give written informed consent.

The study was approved by the institutional review board at each center, and all patients provided written informed consent.

Randomization and study design. In different departments of 7 centers eligible patients concurrently entered one of the two studies: a) to receive active drugs and placebo treatment (cross-over study) or b) to receive only CKLQ treatment (openlabel study).

Patients in the cross-over study were randomized to arm A or arm B. In arm A, patients received one administration of CKLQ, one of placebo and one of tramadol hydrochloride, sequentially. In arm B, patients received one administration of tramadol hydrochloride, one of placebo and one of CKLQ, sequentially. The arm assignments were generated by a computer and written on a card that was put into a sealed envelope. In order to maintain blinding of the study, a doubledummy technique was used to confound the CKLQ tablets with the placebo tablets [CKLQ and placebo tablet (LiZhu Group LiBo Biochemical and Pharmaceutical Co., Ltd.)], and tramadol hydrochloride capsules with the placebo capsules [tramadol hydrochloride capsules and placebo capsule (Liaoning Jingzhou Pharmaceutical Co.)]. The placebo was formulated so as to be identical in color, taste, texture and package to the active drugs.

Each patient was given a box with 3 sequentially numbered drug units. Patients were instructed to take 2 tablets and 2 capsules at a time 3 times. In arm A, the first drug unit was the package with 2 CKLQ tablets (each containing $0.16 \mathrm{mg}$ cobrotoxin, $25 \mathrm{mg}$ tramadol hydrochloride and $50 \mathrm{mg}$ ibuprofen) and 2 placebo capsules. The second unit was the placebo package with 2 placebo tablets and 2 placebo capsules; and the third unit was the active control package with 2 tramadol hydrochloride capsules (each containing $50 \mathrm{mg}$ tramadol hydrochloride) and 2 placebo tablets. In arm B, the sequence of CKLQ and tramadol hydrochloride administration was reversed. If adequate pain relief had not been obtained within $1 \mathrm{~h}$, patients were encouraged to take the next drug unit in the sequence. They were also allowed to take other analgesics which they had used before, but in that case they were disenrolled from the study. Neither patients nor clinicians were aware of the actual contents of each drug unit.

In the open-label study, patients only took 2 tablets of CKLQ at a time and were given the option to continue taking CKLQ for 7 days as long as they had satisfactory pain relief.

Clinical assessment. All patients were observed in a hospital setting, and treated by a hospital team consisting of physicians and nurses experienced in palliative care. At the time of recruit- 


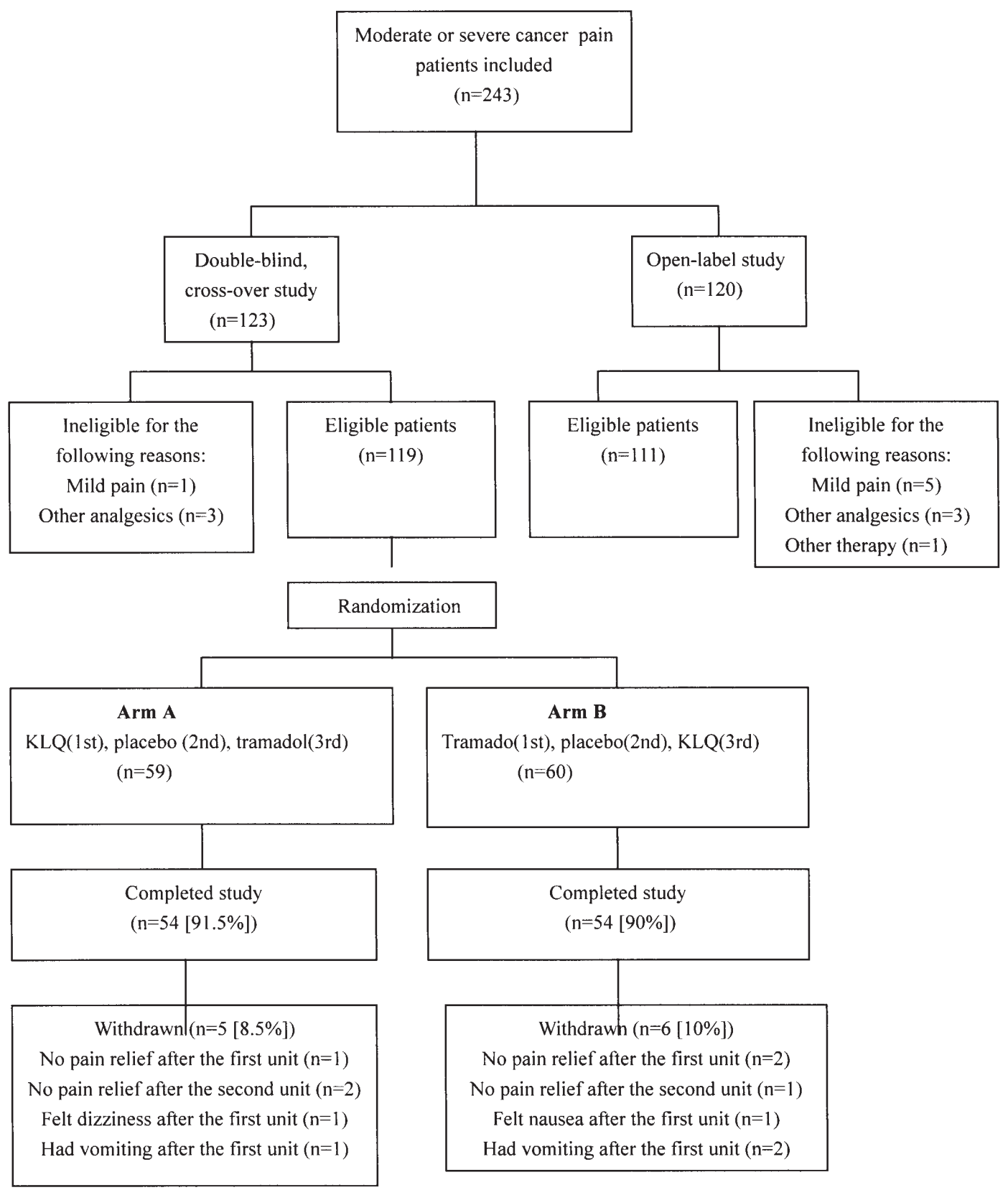

Figure 1. Flow diagram of patients in the study.

ment, patients were asked to keep track of their pain severity, pain experience and pain treatment in a pain diary. Pain intensity at baseline was evaluated by VAS in the presence of an investigator. Patients were required to record the data themselves, and the clinicians merely reminded them to note down any change in pain intensity or AE, after which they discussed pain control with them. After taking each drug unit, patients assessed changes in their pain every $10 \mathrm{~min}$ for $60 \mathrm{~min}$. Pain intensity was subsequently categorized into four levels (no pain, 0 ; mild pain, $>0-4$; moderate pain, $>4-7$; severe pain, $>7-10$ ) according to the VAS rating. The difference in pain intensity and pain response were evaluated by comparing the extent of change in the pain score at different points in time compared with baseline. Once acceptable analgesia was achieved, patients were asked to record at least three kinetic changes in pain intensity and times for each drug unit, as well as their baseline pain intensity and time to dose: i) pain intensity of initial relief and time to relief; ii) pain intensity on reaching mild relief and time to mild pain; iii) pain intensity on reaching maximal relief and time to peak response.

Pain response was classified into complete relief (CR), partial relief (PR) and no change. CR was defined as $100 \%$ pain relief, with a score of 0 on a $0-10$ VAS. PR was defined as a decrease to mild pain, with a pain score of no more than 4 on a $0-10$ VAS. No change was defined as pain that either remained unchanged or that was reduced from severe to moderate at baseline, with a score of $>4$ on VAS after treatment. To further evaluate pain response, we used three time periods to describe the time to response of each drug unit: a) time to onset of pain relief (time from drug ingestion to mild pain relief), b) time to peak pain relief (time from drug ingestion to maximum relief) and c) duration of pain relief.

AEs were spontaneously reported by patients or observed by clinicians. The severity of AEs and the relation with the 
study drug unit (none, possible, probable or definite) were assessed by clinicians.

Statistical analysis. VAS pain intensity at baseline, pain intensity differences and times to response in the three subgroups of the cross-over and open-label studies were compared by one-way analysis of variance (ANOVA). Time to onset of relief, time to peak relief, and duration of relief between two subgroups were estimated by Student's t-test. Pain relief rates were compared by the $\chi^{2}$ test. Fisher's exact test was used to assess differences between subgroups in the proportions of each AE. All data were analyzed using the Statistical Package for the Social Science (SPSS Inc., version 8.0). A two-sided $\mathrm{P}$-value $\leq 0.05$ was considered statistically significant.

\section{Results}

Patients. A total of 230 patients were enrolled into the two studies and were analyzed on an intention-to-treat basis. One hundred and nineteen were assigned to the double-blind, crossover study and 111 entered the open-label study (Fig. 1). Overall, $86.6 \%$ of the patients in the cross-over study and $87.4 \%$ of those in the open-label study had previously used several analgesics in step 2 or 3 of the WHO analgesic ladder. Of the 11 patients who discontinued the study, 6 (54.5\%) did so because of insufficient pain relief and 5 due to AEs. In the cross-over study, 59 patients were randomly assigned to arm A and 60 to arm B and a total of 108 completed the study with three drug units. There was no significant difference in the baseline pain intensity VAS scores of the subgroups of patients in arm A or B taking the same drug unit. Patient characteristics are listed in Table I.

Pain relief in the cross-over study. When patients in arm A and arm B were evaluated together, there were no significant differences in mean baseline pain intensity among the CKLQ, placebo or tramadol hydrochloride subgroups. The mean pain intensity difference at onset of relief and mean time to peak relief were approximately the same among responders taking CKLQ, placebo or tramadol hydrochloride. The only pain intensity difference was noted at peak relief in the placebo subgroup where pain intensity was higher than in the other groups $(\mathrm{P}<0.0001)$. Statistically significant differences were observed in all the clinical responses and time indices in the three subgroups (all, $\mathrm{P}<0.05$ ), except for the mean time to peak relief (about $1 \mathrm{~h}$ ). The clinical relief rates and relief times in both the CKLQ and tramadol hydrochloride subgroups significantly exceeded those of the placebo subgroup (all, $\mathrm{P}<0.05$ ). There were also significant differences in the clinical relief rates and response times between the CKLQ subgroup and tramadol hydrochloride subgroups $(\mathrm{P}<0.0001)$, especially in the mean duration of relief, which was $6.5 \pm 2.7 \mathrm{~h}$ for patients treated with CKLQ and over $2 \mathrm{~h}$ longer than the duration observed $(4.3 \pm 2.6 \mathrm{~h})$ for patients treated with tramadol hydrochloride $(\mathrm{P}<0.0001)$ (Table II).

Of the 35 patients who did not respond to tramadol hydrochloride, 27 (77.1\%) responded to CKLQ. Of the 18 who did not respond to CKLQ, 8 (55.6\%) obtained satisfactory pain control with tramadol hydrochloride.

The effects of the order of administration of the same active analgesics (including CKLQ and tramadol hydrochloride) were
Table I. Baseline characteristics of the patients. ${ }^{a}$

\begin{tabular}{|c|c|c|}
\hline Characteristics & $\begin{array}{c}\text { Cross-over } \\
\text { study } \\
(\mathrm{n}=119)\end{array}$ & $\begin{array}{c}\text { Open-label } \\
\text { study } \\
(\mathrm{n}=111)\end{array}$ \\
\hline \multicolumn{3}{|l|}{ Sex } \\
\hline Male & 51 & 53 \\
\hline Female & 68 & 58 \\
\hline \multicolumn{3}{|l|}{ Age (years) } \\
\hline Mean \pm SD & $52.0 \pm 20.6$ & $55.4 \pm 23.1$ \\
\hline Range & 24-77 & $25-80$ \\
\hline \multicolumn{3}{|l|}{$\begin{array}{l}\text { Primary cancer } \\
\text { (no.) }\end{array}$} \\
\hline Breast & 36 & 26 \\
\hline Lung & 26 & 28 \\
\hline Gastrointestinal & 21 & 18 \\
\hline Other & 36 & 39 \\
\hline \multicolumn{3}{|l|}{ Pain type (no.) } \\
\hline Somatic & 45 & 44 \\
\hline Visceral & 42 & 35 \\
\hline Neuropathic & 17 & 16 \\
\hline Unknown & 15 & 16 \\
\hline \multicolumn{3}{|l|}{ VAS (mm) } \\
\hline Mean & $60.5 \pm 17.2$ & $62.4 \pm 17.6$ \\
\hline \multicolumn{3}{|l|}{ Range } \\
\hline Somatic & $60.3 \pm 17.6$ & $62.9 \pm 18.1$ \\
\hline Visceral & $58.9 \pm 16.4$ & $61.7 \pm 17.3$ \\
\hline Neuropathic & $65.7 \pm 16.3$ & $66.5 \pm 15.4$ \\
\hline Unknown & $59.4 \pm 15.2$ & $62.2 \pm 17.5$ \\
\hline $\begin{array}{l}\text { Duration of pain } \\
\text { (mo.) }\end{array}$ & $5.2 \pm 2.8$ & $6.1 \pm 4.5$ \\
\hline \multicolumn{3}{|l|}{$\begin{array}{l}\text { Prestudy analgesics } \\
\text { (no.) }\end{array}$} \\
\hline Opioid & 103 & 97 \\
\hline Non-opioid & 16 & 14 \\
\hline
\end{tabular}

aplus-minus values are means $\pm \mathrm{SD}$.

also examined. There was no significant difference in clinical response, or time to response provided by the same drug when it was used as the first or the third unit. Specifically, of the 39 $(35.1 \%)$ patients who achieved pain relief with placebo, only $5(4.5 \%)$ obtained CR, and the mean duration of relief was significantly shorter than that of CKLQ $(\mathrm{P}<0.001)$ or that of tramadol hydrochloride $(\mathrm{P}<0.0001)$. Of the 84 patients who responded to the first drug unit, $30(35.7 \%)$ achieved pain relief with the placebo; of the 27 non-responders, 9 (33.3\%) reported achieving pain relief with the placebo (Table III).

Pain relief in the open-label study. In the open-label study, the relief rate of the first dose of CKLQ was $89.2 \%$ (99/111). 
Table II. Comparison of pain intensity at baseline and clinical efficacy variables in cross-over study and in open-label study. ${ }^{\text {a }}$

\begin{tabular}{|c|c|c|c|c|c|c|c|c|}
\hline \multirow[b]{2}{*}{ Variances } & \multicolumn{3}{|c|}{ Cross-over study } & \multirow[b]{2}{*}{ P-value } & \multicolumn{3}{|c|}{ Open-label study } & \multirow[b]{2}{*}{ P-value } \\
\hline & $\begin{array}{l}\text { CKLQ } \\
(n=111)\end{array}$ & $\begin{array}{l}\text { Placebo } \\
(\mathrm{n}=111)\end{array}$ & $\begin{array}{l}\text { Tramadol } \\
(\mathrm{n}=110)\end{array}$ & & $\begin{array}{l}\text { First dose } \\
(n=111)\end{array}$ & $\begin{array}{l}<10 \text { times } \\
(\mathrm{n}=258)\end{array}$ & $\begin{array}{l}\geq 10 \text { times } \\
(\mathrm{n}=373)\end{array}$ & \\
\hline PI at baseline ${ }^{b}$ & $60.6 \pm 17.9$ & $59.5 \pm 18.2$ & $61.5 \pm 17.4$ & 0.526 & $62.3 \pm 16.5$ & $62.6 \pm 16.5$ & $63.7 \pm 15.7$ & 0.458 \\
\hline PID at time to response ${ }^{c}$ & $21.1 \pm 10.4$ & $19.3 \pm 10.7$ & $22.7 \pm 12.9$ & 0.132 & $24.6 \pm 11.5$ & $25.8 \pm 12.8$ & $25.0 \pm 11.4$ & 0.421 \\
\hline $\begin{array}{l}\text { PID at time to the best } \\
\text { response }^{c}\end{array}$ & $43.3 \pm 18.8$ & $37.8 \pm 14.2$ & $43.9 \pm 20.2$ & 0.000 & $42.8 \pm 17.9$ & $43.9 \pm 18.2$ & $42.9 \pm 18.5$ & 0.043 \\
\hline $\mathrm{CR}(\%)^{\mathrm{d}}$ & $23(20.7)$ & $5(4.5)$ & $12(10.9)$ & 0.07 & $25(22.5)$ & $88(34.1)$ & $57(15.3)$ & 0.000 \\
\hline $\operatorname{PR}(\%)^{\mathrm{d}}$ & $70(63.1)$ & $34(30.6)$ & $63(57.3)$ & 0.458 & $74(66.7)$ & $149(57.8)$ & $291(78.0)$ & 0.000 \\
\hline $\mathrm{CR}+\mathrm{PR}(\%)^{\mathrm{d}}$ & $93(83.7)$ & $39(35.1)$ & $75(68.2)$ & 0.011 & $99(89.2)$ & $237(91.9)$ & $348(93.3)$ & 0.357 \\
\hline Time to response $(\min )^{\mathrm{e}}$ & $32.1 \pm 7.1$ & $30.8 \pm 6.8$ & $34.0 \pm 6.6$ & 0.031 & $32.9 \pm 6.9$ & $33.4 \pm 6.5$ & $33.2 \pm 6.5$ & 0.774 \\
\hline $\begin{array}{l}\text { Time to the best response } \\
(\min )^{\mathrm{e}}\end{array}$ & $60.2 \pm 7.7$ & $59.3 \pm 9.3$ & $59.9 \pm 8.7$ & 0.850 & $59.2 \pm 8.2$ & $58.7 \pm 8.6$ & $59.8 \pm 7.8$ & 0.853 \\
\hline Duration of response $(\mathrm{h})^{\mathrm{e}}$ & $6.5 \pm 2.7$ & $1.7 \pm 1.2$ & $4.3 \pm 2.6$ & 0.000 & $6.4 \pm 2.4$ & $6.1 \pm 1.9$ & $5.5 \pm 2.3$ & 0.000 \\
\hline
\end{tabular}

aPlus-minus values are means \pm SD; PI, pain intensity; PID, pain intensity difference. ${ }^{b}$ Data represent mean PI of all patients in cross-over study and in open-label study; analyse by ANOVA. 'Data represent mean PID of responders; analyse by ANOVA. ${ }^{\mathrm{d}}$ Data represent number of responders (\%) in cross-over study and in open-label study; analyse by $\chi^{2}$ test. ${ }^{e}$ Data represent mean value of time variables of responders; analyse by ANOVA.

Table III. Effect of first-unit on response of placebo in crossover study.

\begin{tabular}{lrrr}
\hline & & \multicolumn{2}{c}{ Response to placebo } \\
\cline { 3 - 4 } Response to first-unit & $\mathrm{N}$ & $\mathrm{N}$ & $(\%)$ \\
\hline Keluoqu & & & \\
$\quad$ Responder & 48 & 16 & 33.3 \\
$\quad$ Non-responder & 8 & 3 & 37.5 \\
Tramadol & & & \\
$\quad$ Responder & 36 & 14 & 38.9 \\
$\quad$ Non-responder & 19 & 6 & 31.6 \\
Total & & & \\
$\quad$ Responder & 84 & 30 & 35.7 \\
$\quad$ Non-responder & 27 & 9 & 33.3 \\
\hline
\end{tabular}

The discontinuation rate of the 99 patients was $91 \%(90 / 99)$ and $85 \%(84 / 99)$ of these discontinued because they had left the hospital. The discontinuation rate due to non-achievement of acceptable pain control was $5 \%$ (5/99) while the discontinuation rate for AEs was $1 \%(1 / 99)$. Of the 111 patients in the open-label study, 69 took CKLQ $<10$ times and $42 \geq 10$ times. The total number of times CKLQ was taken by the 111 eligible patients was 631 (range 1-25), with a median of 2 administrations. There were no significant differences in the mean pain intensity difference and overall relief rates between patients taking a specific drug $<10$ times and those taking it $\geq 10$ times. Compared with the first dose subgroup, the overall relief rate in the $<10$ times subgroup did not decrease as only the patients who obtained CR or PR continued with a further dose. The $\mathrm{CR}$ rate in the $\geq 10$ times subgroup decreased significantly $(\mathrm{P}<0.0001)$, while the percentage of $P R$ increased significantly $(\mathrm{P}<0.0001)$. The mean pain intensity difference at peak relief $(42.9 \pm 18.5 \mathrm{~mm})$ in the $\geq 10$ times subgroup was lower than that of the $<10$ times subgroup $(43.9 \pm 18.2 \mathrm{~mm})(\mathrm{P}=0.043)$, although the mean pain intensity at baseline did not differ significantly. No significant differences were observed in the mean time to onset of relief and mean time to peak relief in the $\geq 10$ times subgroup compared with those in the first dose subgroup and in the $<10$ times subgroup (Table II). The mean duration of relief in patients taking treatment $<10$ times was $6.1 \mathrm{~h}$ while it was $5.5 \mathrm{~h}$ in those taking treatment $\geq 10$ times $(\mathrm{P}<0.0001)$.

AEs. The frequency of AEs from CKLQ was similar in the cross-over and open-label studies (Table IV). In the 111 patients in the cross-over study, at least one AE was reported by $47 \%$ of the patients taking tramadol hydrochloride, $39 \%$ of those taking CKLQ and $21 \%$ of those receiving placebo; the $\mathrm{AE}$ was considered by investigators to be possibly, probably, or definitely related to the drug unit.

In the cross-over study, the most frequent AEs caused by CKLQ, tramadol hydrochlorde, and placebo were nausea [36/111 (32.4\%) vs 44/111 (39.6\%) vs $27 / 111(24.5 \%)]$, asthenia [29/111 (26.1\%) vs $15 / 111(13.5 \%)$ vs $2 / 111(1.8 \%)]$, 
Table IV. Primary adverse events in cross-over and in open-label study.

\begin{tabular}{|c|c|c|c|c|c|c|c|c|c|c|c|c|}
\hline \multirow[b]{3}{*}{ Symptom } & \multicolumn{7}{|c|}{ Cross-over study } & \multicolumn{5}{|c|}{ Open-label study } \\
\hline & \multicolumn{2}{|c|}{$\begin{array}{c}\text { CKLQ } \\
(\mathrm{n}=111)\end{array}$} & \multicolumn{2}{|c|}{$\begin{array}{l}\text { Tramadol } \\
(\mathrm{n}=111)\end{array}$} & \multicolumn{2}{|c|}{$\begin{array}{l}\text { Placebo } \\
(\mathrm{n}=110)\end{array}$} & \multirow[t]{2}{*}{ P-value } & \multicolumn{2}{|c|}{$\begin{array}{l}\text { First dose } \\
(\mathrm{n}=111)\end{array}$} & \multicolumn{2}{|c|}{$\begin{array}{l}\text { Total times } \\
(\mathrm{n}=631)\end{array}$} & \multirow[t]{2}{*}{ P-value } \\
\hline & $\mathrm{N}$ & $(\%)$ & $\mathrm{N}$ & $(\%)$ & $\mathrm{N}$ & $(\%)$ & & $\mathrm{N}$ & $(\%)$ & $\mathrm{N}$ & $(\%)$ & \\
\hline Dizziness & 26 & 23.4 & 31 & 27.9 & 17 & 15.5 & 0.539 & 21 & 18.9 & 129 & 20.4 & 0.810 \\
\hline Nausea & 36 & 32.4 & 44 & 39.6 & 27 & 24.5 & 0.328 & 25 & 22.5 & 197 & 31.2 & 0.083 \\
\hline Vomiting & 14 & 12.6 & 17 & 15.3 & 4 & 3.6 & 0.699 & 11 & 9.9 & 84 & 13.3 & 0.404 \\
\hline Sweating & 15 & 13.5 & 26 & 23.4 & 4 & 3.6 & 0.084 & 10 & 9.0 & 65 & 10.3 & 0.727 \\
\hline Palpitation & 11 & 9.9 & 15 & 13.5 & 8 & 7.3 & 0.531 & 9 & 8.1 & 69 & 10.9 & 0.467 \\
\hline Panting & 9 & 8.1 & 8 & 7.2 & 1 & 0.9 & 1 & 7 & 6.3 & 69 & 10.9 & 0.189 \\
\hline Somnolence & 8 & 7.2 & 9 & 8.1 & 6 & 5.5 & 1 & 7 & 6.3 & 52 & 8.2 & 0.614 \\
\hline Exhaustion & 29 & 26.1 & 15 & 13.5 & 2 & 1.8 & 0.029 & 23 & 20.7 & 149 & 23.6 & 0.586 \\
\hline Dysuria & 4 & 3.6 & 3 & 2.7 & 0 & 0 & 0.5 & 4 & 3.6 & 7 & 1.1 & 0.067 \\
\hline Constipation & 8 & 7.2 & 17 & 15.3 & 0 & 0 & 0.089 & 8 & 7.2 & 52 & 8.2 & 0.857 \\
\hline Diarrhoea & 1 & 0.9 & 3 & 2.7 & 1 & 0.9 & 0.31 & 2 & 1.8 & 2 & 0.3 & 0.109 \\
\hline
\end{tabular}

aby comparing CKLQ with tramadol;

Table V. Correlation between adverse events and response of placebo in cross-over study.

\begin{tabular}{lcccc}
\hline & \multicolumn{4}{c}{ Response to placebo } \\
\cline { 2 - 5 } $\begin{array}{l}\text { Adverse } \\
\text { events }\end{array}$ & Responders $(\mathrm{n}=39)$ & Non-responders $(\mathrm{n}=72)$ \\
& $\mathrm{N}$ & $(\%)$ & $\mathrm{N}$ & $(\%)$ \\
\hline Dizziness & 7 & 17.9 & 10 & 13.9 \\
Nausea & 8 & 20.5 & 19 & 26.4 \\
Vomiting & 1 & 2.6 & 3 & 4.2 \\
Sweating & 2 & 5.1 & 2 & 2.8 \\
Palpitation & 2 & 5.1 & 6 & 8.3 \\
Panting & 0 & 0 & 1 & 1.3 \\
Somnolence & 1 & 2.6 & 5 & 6.9 \\
Exhaustion & 1 & 2.6 & 1 & 1.3 \\
Diarrhoea & 0 & 0 & 1 & 1.3 \\
\hline
\end{tabular}

dizziness [26/111 (23.4\%) vs 31/111 (27.9\%) vs $17 / 111$ $(15.5 \%)$ ], sweating [15/111 (13.5\%) vs $26 / 111(23.4 \%)$ vs $4 / 111(3.6 \%)]$ and vomiting $[14 / 111(12.6 \%)$ vs $17 / 111$ $(15.3 \%)$ vs $4 / 111(3.6 \%)]$. There were no significant differences in the frequency of AEs between patients taking CKLQ (188) and tramadol hydrochloride (161) in the crossover study, although asthenia was more common in patients receiving CKLQ $(\mathrm{P}=0.029)$. Most of the AEs were also observed in patients receiving placebo, albeit with a significantly lower frequency. AEs were smilar in the open-label study. There was no relationship between response to placebo and AEs (Table V). Most of drug unit-related AEs were mild to moderate and were easily managed medically. Only 5 patients in the cross-over study ( 2 taking CKLQ, 3 taking tramadol hydrochloride) and 4 in the open-label study discontinued their participation because of AEs.

\section{Discussion}

The present study suggests that CKLQ is an effective and acceptable compound for the treatment of moderate to severe pain in cancer patients. CKLQ has a similar onset of action and degree of pain relief as does tramadol hydrochloride, while its duration of response is significantly prolonged. The CKLQ formulation is characterized by an initial release of tramadol hydrochloride and ibuprofen followed by a delayed release of cobrotoxin. The initial release is fast enough to cause the onset of analgesia (similarly to tramadol hydrochloride), while the delayed release of the remaining element results in a prolonged effect (6).

Although there was a significant difference in response rates and response time between CKLQ and tramadol hydrochloride, a carryover effect for pain intensity at baseline was not observed between the first and the third drug unit in the cross-over study. Administration of placebo between two active analgesics permitted a drug-free period and reduced the potential bias of carryover effect from one active drug phase to the next $(17,18)$. Thiry-five percent of patients were observed to respond to placebo, but their response was independent of whether they responded to the first drug unit, as the CR rate in responders was only $4.5 \%$ and duration of response was only a quarter of that achieved with CKLQ. This may partly be attributed to a true placebo response in which endogenous opioid release or a neurologic down-regulation response may contribute substantially to the improvement of a patient's pain $(19,20)$. 
Preclinical studies have shown that cobrotoxin produces analgesia without the development of cross-tolerance to opioid analgesics (8). We found that most of the patients who had not obtained significant pain relief with tramadol hydrochloride previously achieved a statistically significant benefit from treatment with CKLQ. A similar result was observed for the inverted sequence. These findings seem to indicate that patients who are tolerant to one agent may have the possibility to switch to another. Since it has been well established that there are differences in pain response to different analgesics by different individuals $(17,21)$, it is important to select non-opioid or opioid analgesics to meet the needs of single patients $(22,23)$. CKLQ may present an optional advantage for switching analgesics in patients who do not respond to tramadol hydrochloride. However, the present study was not sufficiently sized to provide a reliable evaluation of the comparative switching effect of CKLQ and tramadol hydrochloride.

The AE profiles of CKLQ and tramadol hydrochloride were similar. However, the incidence of AEs reported in the patients treated with CKLQ was lower than in those receiving tramadol hydrochloride and this was due to its containing $50 \%$ less tramadol hydrochloride and two-thirds less ibuprofen. Asthenia was more frequent in patients receiving CKLQ and this was probably related to the cobrotoxin component which has an effect on peripheral sites and produces post-synaptic blocking of the cholinergic receptor of the skeletal muscle endplate $(8,24-26)$. The incidence of AEs reported in the patients treated with placebo was somewhat high, which may be a result of the bias reduction in the double blind study (17). The finding that the incidence of placebo AEs was not related to response suggests that the AEs and response to placebo did not tend to occur in the same individual.

Given that hospitalization costs (excluding drugs) are low in China (3 USD a day), all the patients in the study could be observed in a hospital setting [different places can influence the results of analgesia $(27,28)]$ and the kinetic changes in pain intensity at different time-points could be monitored. This study was not designed to assess the change in pain intensity at fixed time-points, which made it difficult to pinpoint the exact time to response, time to the best response and duration of response of CKLQ. In order to determine the time to response, clinicians asked patients to evaluate pain intensity at 10-min intervals over a 1-h period after taking one drug unit. However, a greater frequency of ward rounds would in itself create a placebo effect and, once the patients responded to the drug unit, clinicians could discontinue their rounds until the next drug unit in the sequence.

There were two main areas of methodologic weakness in our study. Firstly, the sample size of the cross-over study was not sufficiently powered to determine the statistically significant differences in the response and the incidence of AEs of CKLQ and of tramadol hydrochloride. Secondly, it is premature to conclude that CKLQ could be used to provide a reliable evaluation of the comparative switching effect of CKLQ and tramadol hydrochloride to control chronic moderate to severe cancer pain, because response and safety were evaluated only once after switching in the single dose design. In fact, alternative delivery systems for cobrotoxin derivates has been recently suggested (29).
Finally, in the open-label study, we expected that patients would continue CKLQ treatment for 7 days or until pain relief became adequate, and yet the discontinuation rate was high. Several factors contributed to failure of patients to continue CKLQ treatment including having to leave the hospital due to economic reasons or fear of AEs from long-term administration of the trial drugs. Given this limitation, the tolerance of CKLQ remains to be defined.

In conclusion, this is the first randomized, placebocontrolled, double-blind study of a cobrotoxin-related analgesic compound for the treatment of moderate to severe cancer pain. CKLQ was found to have onset properties and a time to peak activity similar to those of tramadol hydrochloride, but a higher pain relief rate and a longer duration of response. In particular, there could be incomplete cross-tolerance with tramadol hydrochloride.

\section{Acknowledgements}

This study was supported by the Drug Assessment Center of the National Ministry of Health, P.R. China. The design, conduct and data management of this study were supported by LiZhu Group LiBo Biochemical and Pharmaceutical Co. Ltd., Shanghai, P.R. China. We are indebted to Marco Maltoni at Istituto Oncologico Romagnolo, Forlì, Italy, for his valuable suggestions in the preparation of this report and Oriana Nanni for her supervision of the statistical analysis.

\section{References}

1. Hanks GW and Justins DM: Cancer pain: management. Lancet 339: 1031-1036, 1992

2. Bruera E, Belzile M, Pituskin E, et al: Randomized, double-blind, cross-over trial comparing safety and efficacy of oral controlledrelease oxycodone with controlled-release morphine in patients with cancer pain. J Clin Oncol 16: 3222-3229, 1998.

3. Jacox A, Carr DB and Payne R: New clinical-practice guidelines for the management of pain in patients with cancer. N Engl J Med 330: 651-655, 1993.

4. Klepstad P, Kaasa S, Cherny N, et al: Research Steering Committee of the EAPC. Pain and pain treatments in European palliative care units. A cross sectional survey from the European Association for Palliative Care Research Network. Palliat Med 19: 477-484, 2005

5. Zech DFJ, Grond S, Lynch J, et al: Validation of world health organization guidelines for cancer pain relief: a 10 year prospective study. Pain 63: 65-71, 1995.

6. Park MH, Song HS, Kim KH, et al: Cobrotoxin inhibits NF-kappa $\mathrm{B}$ activation and target gene expression through reaction with NF-kappa B signal molecules. Biochemistry 44: 8326-8336, 2005.

7. Pu XC, Wong PTH and Gopalakrishnakone P: A novel analgesic toxin (hannalgesin) from the venom of king cobra (ophiophagus hannah). Toxicon 33: 1425-1431, 1995.

8. Chen RZ and Robinson SE: The effect of cholinergic manipulations on the analgesic response to cobrotoxin in mice. Life Sci 1425: 1949-1954, 1990.

9. Raber M, Hofmann S, Junge K, et al: Analgesic efficacy and tolerability of tramadol $100 \mathrm{mg}$ sustained-release capsules in patients with moderate to severe chronic low back pain. Clin Drug Invest 17: 415-423, 1999.

10. Grond S, Radbruch L, Meuser T, et al: High-dose tramadol in comparison to low-dose morphine for cancer pain relief. J Pain Symptom Manage 18: 174-179, 1999.

11. Palangio M, Damask MJ, Morris E, et al: Combination hydrocodone and ibuprofen versus combination codeine and acetaminophen for the treatment of chronic pain. Clin Ther 2: 879-892, 2000.

12. Mercadante S, Casuccio A, Agnello A, et al: Analgesic effects of non-steroidal-inflammatory drugs in cancer pain due to somatic or visceral mechanisms. J Pain Symptom Manage 17: 351-356, 1999. 
13. Collins SL, Moore RA, McQuay HJ: The visual analogue pain intensity scale: What is moderate pain in millimeters? Pain 72: 95-97, 1997.

14. Serlin RC, Mendoza TR, Nakamura Y, et al: When is cancer pain mild, moderate or severe? Grading pain severity by its interference with function. Pain 61: 277-284, 1995.

15. De Conno F, Caraceni A, Gamba A, et al: Pain measurement in cancer patients: a comparison of six methods. Pain 57: 161-166, 1994.

16. Bruera E, Sloan P, Mount B, et al: A randomized, double-blind, double-dummy, crossover trial comparing the safety and efficacy of oral sustained-release hydromorphone with immediate-release hydromorphone in patients with cancer pain. J Clin Oncol 14: 1713-1717, 1996.

17. Hagen NA and Babul N: Comparative clinical efficacy and safety of a novel controlled-release oxycodone formulation and controlled-release hydromorphone in the treatment of cancer pain. Cancer 79: 1428-1437, 1997.

18. Ter Riet G, De Craen AJ, De Boer A and Kessels AG: Is placebo analgesia mediated by endogenous opioid? A systematic review. Pain 76: 273-275, 1998.

19. Roelofs J, ter Riet G, Peters ML, et al: Expectations of analgesia do not affect spinal nociceptive R-III reflex activity: an experimental study into the mechanism of placebo-induced analgesia. Pain 89: 75-80, 2000

20. Mercadante S, Casuccio A, Fulfaro F, et al: Switching from morphine to methadone to improve analgesia and tolerability in cancer patients: a prospective study. J Clin Oncol 19: 2898-2904, 2001.

21. Mercadante S, Casuccio A, Agnello A, et al: Morphine versus methadone in the pain treatment of advanced-cancer patients followed up at home. J Clin Oncol 16: 3656-3661, 1998.

22. Kaplan R, Parris WCV, Citron ML, et al: Comparison of controlled-release and immediate-release oxycodone tablets in patients with cancer pain. J Clin Oncol 16: 3230-3237, 1998.

23. Fels G, Plumer-Wilk R, Schreiber M and Maelicke A: A monoclonal antibody interfering with binding and response of the acetylcholine receptor. J Biol Chem 261: 15746-15754, 1986.
24. Utkin YN, Kukhtina VV, Kryukova EV et al: 'Weak toxin' from Naja Kaouthia is a non-toxin antagonist of alpha 7 and muscle-type nicotinic acetylcholine receptors. J Biol Chem 276 : 15810-15815, 2001.

25. Sine SM and Taylor P: The relationship between agonist occupation and the permeability response of the cholinergic receptor revealed by bound cobra alpha-toxin. J Biol Chem 255 : 10144-10156, 1980.

26. Waltz M, Kriegel W and van't Pad Bosch P: The social environment and health in rheumatoid arthritis: marital quality predicts individual variability in pain severity. Arthritis Care Res 11: 356-374, 1998.

27. Stiefel F: Psychosocial aspects of cancer pain. Support Care Cancer 1: 130-134, 1993.

28. Petzke F, Radbruch L, Sabatowski R, et al: Slow-release tramadol for treatment of chronic malignant pain - an open multicenter trial. Support Care Cancer 9: 48-54, 2000.

29. Li Y, Jiang HL, Zhu KJ, et al: Preparation, characterization and nasal delivery of alpha-cobrotoxin-loaded poly (lactide-coglycolide)/polyanhydride microspheres. J Control Release 108 10-20, 2005.

\section{Notes}

The Keluoqu investigators group included the following: S.T. Song and J.M. Xu, Beijing 307 Hospital, Beijing; F.Y. Feng and X.H. He, Cancer Hospital, Chinese Academy of Medical Sciences, Beijing; L.G. Xu, Cancer Hospital, Shanghai Medical University, Shanghai; F.L. Huang and J. Cheng, Jiangsu Province Cancer Hospital, Nanjing; Y. Yang and M. Cui, Kunming the PLA General Hospital, Kunming; G.R. Xie, Tianjin Cancer Hospital, Tianjin; C.Z. Zhang and H.X. Ren, The Third Teaching Hospital, Kunming Medical University, Kunming; M. Bruno and A. Paradiso, National Cancer Institute, Bari, Italy. 